\section{P23 USING LATENT CLASS ANALYSIS TO EXPLORE DIETARY PATTERNS AND THEIR ASSOCIATIONS BETWEEN SOCIODEMOGRAPHIC CHARACTERISTICS, FOOD SOURCES, DIETARY DIVERSITY, AND FOOD INSECURITY IN SMALL ISLAND DEVELOPING STATES}

\begin{abstract}
${ }^{1}$ Eden Augustus*, ${ }^{2}$ Diyya Bhagtani, ${ }^{3}$ Emily Haynes, ${ }^{4}$ Arlette St Ville, ${ }^{5}$ Viliamu lese, ${ }^{5}$ Jioje Fesaitu, ${ }^{6}$ Florian Kroll, ${ }^{1}$ Ian Hambleton, ${ }^{7}$ Sara Benjamin-Neelon, ${ }^{2,3}$ Nigel Unwin. ${ }^{1}$ The George Alleyne Chronic Disease Research Centre, The University of the West Indies, Bridgetown, Barbados; ${ }^{2}$ MRC Epidemiology Unit, University of Cambridge, Cambridge, UK; ${ }^{3}$ European Centre for Environment and Human Health, University of Exeter, Turo, UK; ${ }^{4}$ Faculty of Food and Agriculture, The University of the West Indies, St. Augustine, Trinindad and Tobago; ${ }^{5}$ Pacific Centre for Environment and Sustainable Development (PaCE-SD), The University of the South Pacific, Suva, Fiji; ${ }^{6}$ Institute for Poverty, Land and Agrarian Studies (PLAAS), University of the Western Cape and DSI-NRF Centre of Excellence in Food Security, Cape Town 7535, South Africa; 'Department of Health, Behaviour and Society, Johns Hopkins Bloomberg School of Public Health, Baltimore, Maryland, USA
\end{abstract}

\subsection{6/jech-2021-SSMabstracts.112}

Background The high burden of disease related to malnutrition in Small Island Developing States (SIDS) has been exacerbated by increasing levels of food insecurity (FI) and loss of food sovereignty. Internationally, household, or individual level FI is associated with poorer diets and nutritional status. Our study aimed to investigate whether there are distinct dietary patterns, and if so whether they are associated with sociodemographic characteristics (SDC), dietary diversity scores (DDS), food sources and experience of food insecurity in adults in two SIDS: Fiji and St. Vincent and the Grenadines (SVG).

Methods A cross-sectional household survey was conducted, recruiting adults and adolescents ( $>15$ years) from 95 and 86 households in rural and urban Fiji $(n=186)$ and SVG $(n=147)$, respectively. Data were collected by trained interviewers using standard tools with a 24-hour recall component, adapted to the local food environments. Latent class analysis (LCA) was conducted using 13 food groups, and moderate to severe FI categories derived from the Food Insecurity Experience Scale (FIES). LCA was undertaken in R, and best fit solutions were based on the AIC results. Differences between the LCA derived classes were examined using one-way ANOVA and Pearson Chi-Squared tests.

Results In both Fiji and SVG the best fit LCA derived 3 distinct dietary patterns, across which were differences in DDS $(p<0.001)$. In Fiji dietary patterns were associated with age $(p=0.042)$, sex $(p=0.047)$, and rural residence $(p=0.005)$. In SVG there were no associations with SDCs. In both Fiji and SVG dietary patterns were associated with > weekly sourcing of food by borrowing/exchanging $(p<0.001)$, and in both settings sourcing food in this way was most frequent in the dietary pattern with the highest DDS. In SVG > weekly sourcing food from a small shop varied by dietary pattern $(p=0.002)$, being highest in that with the lowest DDS. In Fiji FI was associated with dietary patterns $(\mathrm{p}=0.011)$, ranging from $6.7 \%$ $(95 \% \mathrm{CI} 3.0,14.1)$ to $26.5 \%(95 \% \mathrm{CI} 14.3,43.7)$. In SVG there was no apparent association between FI and dietary pattern $(\mathrm{p}=0.507)$, and FI in the whole sample was $35.4 \%(95 \%$ CI 27.6, 43.1).

Conclusion Food environment and culture likely accounts for differences across settings. However, associations were found among dietary patterns and SDC, FI and food sources in at least one setting, with sourcing food through borrowing/bartering prominent among groups in both settings, with the highest DDS. This highlights the need for further research to inform policies.

\section{P24 PENETRATION AND PRESENTATION OF FRONT-OF-PACK NUTRITION LABELLING IN UK SUPERMARKET WEBSITES: PRELIMINARY SURVEY RESULTS}

Sally Moore*, Aimee Hall. School of Food Science and Nutrition, University of Leeds, Leeds, West Yorkshire, UK

\subsection{6/jech-2021-SSMabstracts. 113}

Background The availability and format of Front-of-Pack nutrition labels (i.e. Traffic Lights) on product packaging supports consumers' use of this information when making food choices. ${ }^{1}$ For products sold online, research around 2015 has indicated inconsistences in the presentation of nutrition information across supermarket websites ${ }^{2}$ and a lack of use of product information by online shoppers. ${ }^{3}$ However, online grocery shopping is currently growing in popularity in the UK and has the potential to support the selection and purchase of healthier foods via the provision of appropriate product nutrition information/signposting. ${ }^{4}$ This study aims to assess the penetration of FOP nutrition label information on products sold in UK online supermarkets. Variations in the availability and presentation of this information by online retailer, brand, product category and nutritional composition are also to be explored.

Methods Conducted during 2020-2021, products sold within the entire (chilled) beef burger, Greek yoghurt and muesli categories of five UK online supermarkets were surveyed. Data was collected on presence, type and format components of FOP labelling together with information on product attributes, including brand and nutritional composition. The latter was used to calculate FOP traffic light colour coding according to UK criteria. ${ }^{5}$ Preliminary analysis performed included descriptive statistics presented by retailer, product brand and overall nutritional composition

Results Findings show that 59\% of the total of 244 surveyed products displayed FOP labelling, with variations in penetration across retailers. Where FOP labelling was declared, 62\% of products displayed this in formats compliant with one or more elements of 'best practice' guidance on the presentation of this information on-pack. ${ }^{6}$ Overall, greater penetration of FOP traffic light labels was found on products of supermarkets' own brand (64\%), or those with $\leq 1$ red traffic lights (96\%), compared to branded products $(19 \%)$ or those with $\geq 2$ red traffic lights $(1 \%)$.

Conclusion Initial findings suggest the penetration of FOP nutrition labelling on products sold in UK online supermarkets is variable within and between retailers. Further research is warranted. To ensure the consistent availability and presentation of FOP nutrition label information across all product types sold in UK supermarket websites, there is a need for presentational guidance.

\section{REFERENCES}

1. DHSC. (2020). Department of Health and Social Care. Building on the success of front-of-pack nutrition labelling in the UK: a public consultation. UK Government and Food Standards Agencies. 50

2. Stones C. Online food nutrition labelling in the UK: how consistent are supermarkets in their presentation of nutrition labels online? Public Health Nutr 2016:19:2175-2184.

3. Benn Y, Webb TL, Chang BPI, et al. What information do consumers consider and how do they look for it, when shopping for groceries online? Appetite 2015;89:265-273.

4. Jilcott Pitts SB, Ng SW, Blitstein JL, et al. Online grocery shopping: promise and pitfalls for healthier food and beverage purchases. Public Health Nutr 2018;21:3360-3376.

5. DoH. (2016). Department of Health. Guide to creating a front of pack (FoP) nutrition label for pre-packed products sold through retail outlets. 
6. IGD. (2017). Designing, presenting and positioning front of pack nutrition labels: a best practice guide based on consumer research. https://www.igd.com/socialimpact/health/engaging-consumers/labelling/designing-front-of-pack-nutrition-labels (accessed March 2021).

\section{P25 BUILDING A COMMUNITY ADVISORY BOARD TO RESEARCH CLIMATE CHANGE IMPACTS ON CONSUMPTION OF FOOD BIODIVERSITY OF INDIGENOUS COMMUNITIES IN THE PERUVIAN AMAZON}

\begin{abstract}
${ }^{1}$ Carol Zavaleta-Cortijo*, 'Andrea Valdivia-Gago, ${ }^{1}$ Rosalia Montero, ${ }^{1}$ Rosa Silvera, ${ }^{2}$ Delfina Catip, ${ }^{2}$ Rocilda Nunta, ${ }^{3}$ Connie Fernandez-Neyra, ${ }^{4}$ Guillermo Lancha, ${ }^{4}$ Pedro Pizango, ${ }^{5}$ Juan-Pablo Aparco. ${ }^{1}$ Facultad de Salud Publica (FASPA), Universidad Peruana Cayetano Heredia, Lima, Peru; ${ }^{2}$ Programa Mujer, Asociacion Interetnica de Desarrollo de la Selva Peruana (AIDESEP), Lima, Peru; ${ }^{3}$ Hospital Santa Gema, Direccion Regional de Salud Loreto, Yurimaguas, Peru; ${ }^{4}$ Pueblo Shawi, Yurimaguas, Peru; ${ }^{5}$ Centro Nacional de Alimentacion y Nutricion, Instituto Nacional de Salud, Lima, Peru
\end{abstract}

\subsection{6/jech-2021-SSMabstracts. 114}

Background A sustainable planet for everyone requires improving the nutrition of minorities and historically excluded populations. Indigenous people in South America are among those more affected by multiple forms of malnutrition, and the Amazon ecosystem is increasingly experiencing dramatic changes including more frequent and intense extreme weather events. In the context of a research project aimed to investigate the potential of food biodiversity to protect Amazon Indigenous people nutrition in the light of more intense and severe flooding, we have created a Community Advisor Board $(\mathrm{CAB})$ to increase the impact of the project, and to provide with advice to conduct a meaningful and cultural adequate implementation of the project.

Methods One climatologist, two senior nutritionists (male and female) and two women Indigenous leaders, were invited to participated in the $\mathrm{CAB}$ through official letters by email. All except the climatologist, replied positively. As part of the first year we have developed three online working meetings (1 to 2 hrs each). The $\mathrm{CAB}$ have provided advice to adapt an online dietary assessment tool (myfood24), to perform a pilot study for creating a photo album of Indigenous food portions, and to advise on how to approach Indigenous communities nutritional needs during the still on going COVID-19 pandemic in the Peruvian Amazon.

Results Four critical points were highlighted by the CAB for increasing the impact of the project: 1) to seek to increase the resilience of Indigenous food diets to climate change for example by identifying what crops were 'climate resistant' according to Indigenous knowledge, 2) It was recommended to collect recipes that have protected indigenous communities during COVID-19 since 'food' was also used as 'medicine' among Indigenous people, 3) the investigation of food biodiversity informs Indigenous food resilience this was mentioned as being highly important to protect indigenous nutrition during extreme weather events and even during COVID-19, and 4) It was recognized that gender differences were important to consider because of biological differences between male and female, for food consumption (e.g. portion sizes and food distribution within households vary between sexes) and because women were the protectors and safeguarders of knowledge to produce and collect plants from the forest

Conclusion The $\mathrm{CAB}$ was stablished with two Indigenous and two non-Indigenous members. The $\mathrm{CAB}$ encouraged the researchers to share the data collected with other indigenous groups in the Amazon to increase their resilience to climate change and to inform peruvian authorities about the nutrition content of Indigenous foods

\section{P26 EXPLORING OPINIONS ABOUT A MINDFULNESS-BASED INTERVENTION FOR DISORDERED EATING AMONG UNIVERSITY STUDENTS: A QUALITATIVE STUDY}

${ }^{1}$ Ella Altair*, ${ }^{1}$ Eleni Karasouli, ${ }^{2}$ Caroline Meyer, ${ }^{1}$ Oyinlola Oyebode. ${ }^{1}$ Warwick Medical School, University of Warwick, Coventry, UK; ${ }^{2}$ Warwick Manufacturing Group, University of Warwick, Coventry, UK

\subsection{6/jech-2021-SSMabstracts. 115}

Background It is not uncommon that university students may exhibit disordered eating behaviours because of the various challenging factors in their age-group. Research points to the high prevalence of subclinical eating disorders (EDs) that do not require clinical attention among young adults. We aimed to conduct a qualitative study among university students with subclinical EDs to explore students' attitudes and opinions about a potential mindfulness-based intervention.

Methods Six online focus groups and five interviews took place using Microsoft Teams among young adult students. Participants were recruited online through university mailing lists and were screened for subclinical EDs to ensure eligibility. Those requiring clinical attention were excluded. Discussions lasted 60-90 minutes and focused on reasons of disordered eating behaviours, acceptability of the proposed intervention themes and students suggestions and opinions about the intervention. The study was approved by Biomedical \& Scientific Research Ethics Committee (BSREC) of the University of Warwick.

Results 23 participants from seven departments took part in the study, most of them were white females aged between 18 and 22. Results revealed the acceptability of mindfulness intervention as well as intuitive eating. Students' main reasons for disordered eating were mental health challenges, especially stress; and social influences, especially social media. University lifestyle elements were believed to have minimal impact on the occurrence of ED behaviours. Students preferred the intervention to be with a group respecting confidentiality, focused on practicals, personalized where possible, encouraging participants to attend through providing effective solutions yielding a change in their eating behaviours or through the reassurance of being with a group of participants going through similar experiences.

Conclusion Mindfulness-based intervention might be applied among university students with subclinical EDs. Participants might prefer different kinds of mindfulness practices such as sitting meditations or moving meditations. Other approaches may need to be combined with mindfulness for those who believe this is needed, such cognitive behavioural therapy practices. Interventions might consider creating a reassuring and confidential space for participants through a group, grouping participants with similar behaviours together, creating a helpful environment to commit to the practices such as providing a specific form of practice and a progress checker. University-student participants with sub-clinical EDs might be knowledgeable about healthy eating and EDs and willing to improve their eating behaviours but do not know where/how to start. 